\title{
Mespilus germanica (MG) and Tribulus terrestris (TT) Used as Biosorbents for Lead Removal from Aqueous Solutions: Adsorption Kinetics and Mechanisms
}

\author{
Majid Ehteshami $\mathbb{D}^{1},{ }^{1}$ Hamidreza Zolfaghari ${ }^{D},{ }^{1}$ Marjan Salari ${ }^{(D},{ }^{2}$ and Ehsan Teymouri ${ }^{3}{ }^{3}$ \\ ${ }^{1}$ Department of Civil Engineering, K.N. Toosi University of Technology, Tehran, Iran \\ ${ }^{2}$ Department of Civil Engineering, Sirjan University of Technology, Sirjan, Iran \\ ${ }^{3}$ Department of Civil and Construction Engineering, Faculty of Engineering and Science, Curtin University Malaysia, \\ Miri, Malaysia
}

Correspondence should be addressed to Marjan Salari; salari.marjan@gmail.com

Received 8 September 2021; Revised 26 October 2021; Accepted 12 November 2021; Published 27 November 2021

Academic Editor: Santiago Garcia-Granda

Copyright (c) 2021 Majid Ehteshami et al. This is an open access article distributed under the Creative Commons Attribution License, which permits unrestricted use, distribution, and reproduction in any medium, provided the original work is properly cited.

\begin{abstract}
Today, most countries around the globe are facing water resources restrictions, and it is predicted freshwater resources will be more valuable than oil wells in the next century. In the present study, the ability of lead removal using both powders of Mespilus germanica (MG) and Tribulus terrestris (TT) seeds and optimization of the adsorption process have been investigated. Four main parameters were selected for experimental design, namely, $\mathrm{pH}$, time of contact, the ratio of adsorbent to solution volume, and initial concentration of lead in solution, and the optimization of effective parameters on lead adsorption was performed based on central composite design (CCD) under response surface methodology (RSM). According to the statistical results, the proposed model for MG and TT is confirmed with 0.95 and 0.96 correlation coefficient and 0.92 and 0.94 adjusted correlation coefficient, respectively. The results of parameter optimization also showed that both adsorbents have the acceptable ability to adsorb lead from aqueous solutions. Under the optimum conditions with the initial lead concentration of $10 \mathrm{mg} / \mathrm{l}, \mathrm{MG}$ powder had better performance in lead adsorption of $96.04 \%$, and TT powder also had an acceptive performance of $93.20 \%$. Moreover, the MG and TT adsorbents have the most accordance with the Freundlich and D-R isotherms, respectively.
\end{abstract}

\section{Introduction}

Water shortage is becoming a serious crisis, and it is predicted freshwater resources will be more valuable than oil wells in the next century. Consequently, the usage of low quality of water resources such as seas and oceans, industrial, agricultural, and urban wastewater has fascinated the attention of many countries. The usage of these resources requires planning to improve their quality, and more extensive research has recently been conducted on modeling and possible ways to boost the quality of them and remove contaminants and impurities [1-4].

Heavy metals are referred to as metallic elements with relatively high densities and even toxic effects at low concentrations. Therefore, these metals are among the most dangerous contaminants that, through human activity such as infiltration of landfill leachates into groundwater or terrestrial sources, such as minerals with heavy metal compounds present in the earth's crust, can find a way to water sources $[5,6]$. The most well-known metals in this group include lead, cadmium, arsenic, zinc, silver, mercury, nickel, chromium, copper, and iron. Accurate measurement of the concentration of these elements has caused the standard amount for the maximum allowable concentration of these elements in drinking water to be accurately announced by the legislature. For example, the EPA set the standard maximum permissible lead concentration for drinking water at $0.015 \mathrm{mg} / \mathrm{L}$ in 2011 [7]. Nowadays, more 
effective methods have been performed to remove heavy metals from aqueous solutions such as chemical sequestration, ion exchange, electrochemical purification, membrane purification, and adsorption, which are often cost a lot or have low performances. Biosorption is one of the suitable methods to reduce the concentration of heavy metals, which is environmentally friendly as well as efficient and economic $[8,9]$.

In recent years, the use of biosorption in the separation of metals has become particularly important and has gradually become an important issue in the control of metal contamination. These adsorbents have the property of repelling metals and are used to reduce the concentration of heavy metal ions in solution from PPM to ppb (one component per billion components) [10].

In terms of biosorption, extensive researches have been performed. In 2019, Terán et al. assessed the capability of montmorillonite clay for lead removal from water [11]. Mousavi et al. examined the bioabsorption using a mixed culture of lead algae biomass from an aqueous solution. In this study, four main variables of biosorbent dose, initial lead concentration, contact time, and initial $\mathrm{pH}$ on lead removal efficiency were investigated. The results indicated that the maximum removal of lead under optimal conditions including biosorbent dose, initial concentration of lead, contact time, and initial $\mathrm{pH}$ of $5.52 \mathrm{~g} / \mathrm{l}, 100 \mathrm{mg} / \mathrm{l}, 110 \mathrm{~min}$, and 6 equal to $95.43 \%$, respectively [12]. Li et al. developed a novel strategy for phosphorous and $\mathrm{Pb}(\mathrm{II})$ removal sequentially from water by Chlorella sp. In this study, the optimal biomass production in cultures above $280 \mathrm{mg} / \mathrm{L}$ and the biosorption functions of biosorbents from different concentrations of phosphorus cultures were investigated. The results indicated that the optimum $\mathrm{pH}$ for adsorption was 6.0, and the adsorption kinetics and isotherms were suitable for quasi-quadratic and Langmuir models for all biosorbents, respectively [13].

Salehi et al. showed that using Pomegranate core as biosorption can lead to $18.4 \mathrm{mg} / \mathrm{L}$ lead adsorption in the laboratory conditions $(\mathrm{pH}=4.0$, initial pomegranate concentration $=10 \mathrm{~g} / \mathrm{L}$, and duration $=30 \mathrm{~min}$ ) [14].

Joseph et al. provide a review that focused on the removal of heavy metals by means of low-cost adsorbents in developing countries instead of common methods such as membrane filtration, activated carbon adsorption, and electrocoagulation. In this review, they evaluated the usage of adsorbents in four main categories, namely, agricultural waste, naturally occurring soil and mineral deposits, aquatic and terrestrial biomass, and other locally available waste minerals [15]. Teymouri et al. represented that using mineral and low-cost adsorbents such as zeolite, pumice, perlite, and leca in porous concrete can be an effective way to reduce urban runoff pollution [16] and a new approach as a pretreatment for municipal wastewater [17]. In these experiments, the urban runoff passed through the filtration column with sand at the end, and COD, BOD, TSS, and turbidity decreased up to $90 \%$ [17], and wastewater characteristics such as BOD, COD, TSS, and turbidity were reduced up to $40 \%[18]$.
In this research, the ability of lead removal using both powders of Mespilus germanica (MG) and Tribulus terrestris (TT) seeds, which have not been studied before, has been investigated. Also, optimization of lead removal by biological adsorption process using central composite design (CCD) based on response surface methodology (RSM) has been performed. Finally, adsorption isotherms and kinetics for each adsorbent were investigated.

\section{Materials and Methods}

Reagent grade chemicals were used in analytical. Initially, $319.7 \mathrm{mg}$ of nitrate was added to $1,000 \mathrm{~mL}$ of water to produce a lead solution at a concentration of $200 \mathrm{mg} / \mathrm{L}$. Nitric acid $\left(\mathrm{HNO}_{3}, 0.1 \mathrm{M}\right)$ and sodium hydroxide $(\mathrm{NaOH}, 0.1 \mathrm{M})$ were purchased from Merck (Germany). Among the equipment used in this research, including $\mathrm{pH}$ measurement, Water Quality Meter model 8603 Handheld IP67 made in Taiwan, Shaker model PVR2080 made by PECO company, and atomic absorption device AAS-240 made by Varian company from Australia and measured by the flame method were used.

2.1. Mespilus germanica (MG). Mespilus germanica, which is shown in Figure 1, is a fruit with a high level of acidity and is useful for controlling blood pressure, lipids, and blood sugar, treating kidney stones, and digestive problems. Its plant belongs to the Rosaceae family and is also related to apples, pears, and hawthorns. Its tree is usually between 3 and $6 \mathrm{M}$ high and with a lifespan of 30 to 50 years; it is a relatively short-lived tree. The flesh of the caraway changes from white to brown when ripe. Its chemical composition includes sugar, malic acid, citric acid, tartaric acid, tannin acid, and boric acid. The core of MG is inedible and toxic due to its cyanohydrin acid and is useless in the agricultural industry and disposed of as waste. It is therefore available as a cheap and abundant adsorbent [19].

2.2. Tribulus terrestris (TT) Seeds. Tribulus terrestris (TT), which is presented in Figure 2, is a herbaceous plant that has a wide distribution in different parts of the world and is considered a weed. From the family of herbaceous Zychophyllaceae, it is an annual plant with dormant stems with wide branches on the soil surface and small yellow flowers. When the fruit ripens, its five parts separate and disperse. Each of these five parts is prone on the outer surface. The color of its fruits is yellowish green and odorless and has a distinct taste. Chemical components of this plant include resin, beech, alkaloid, polyphenols, and minerals such as calcium, phosphorus, iron, sodium, potassium, sulfur, nitrogen, and chlorine. In this study, the fruit of this plant is used as a low-cost biosorbent in removing lead from aqueous solutions [20].

At first, the adsorbents were prewashed with freshwater and then washed twice with distilled water to remove the minerals and impurities from the surface of the adsorbents. Afterward, it was dried at room temperature for 72 hours 

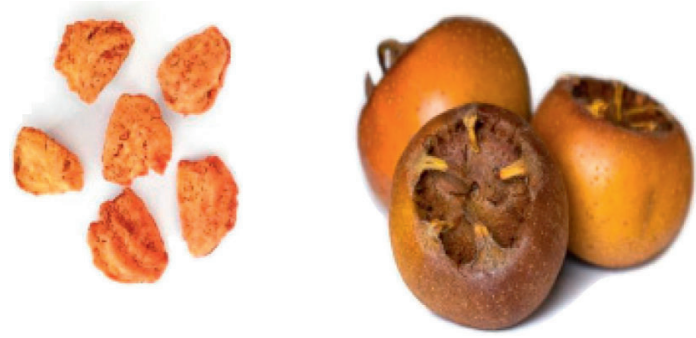

Figure 1: Mespilus germanica and its core.
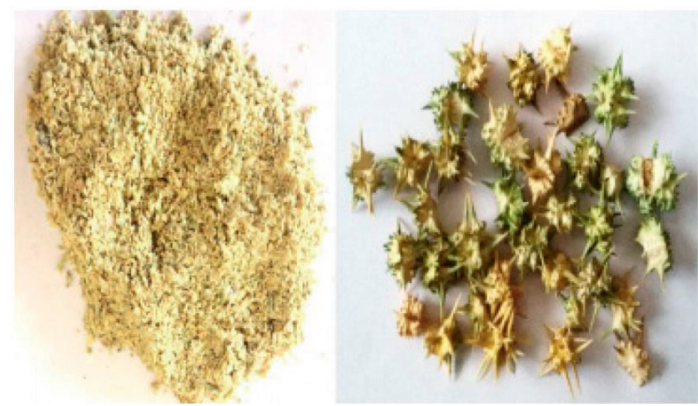

FIgURE 2: Tribulus terrestris seeds and their powder.

before powdering with an electrical chopper with the intention of particle homogenization. Finally, the powders were passed through sieve No. $18(D=1 \mathrm{~mm})$.

2.3. Conducting the Experiments. RSM, a statistical tool that includes a set of mathematical techniques, was used for designing experiments, modeling, and analyzing topics. In that process, response is affected by several input variables, and optimization of this specific response is performed simultaneously [21-24].

Four main variable parameters, namely, $\mathrm{pH}$, time of contact, the dose of adsorbent, and initial lead concentration in solution were considered. In order to design the optimization experiments and discover the highest absorption percentages, central composite design (CCD) method was used, and the number of experiment and variable levels in each experiment was determined. In the modal center mode, the maximum and minimum boundaries are specified by the code of the levels $+\alpha$ and $-\alpha$ [25-27].

Alpha $(\alpha)$ is the distance of each axial point (also called star point) from the center in a central composite design, as follows [22-26]:

$$
a=\left(2^{k}\right)^{0.25} .
$$

Experimental results of reconstructed images were obtained by CCD; a second-order (quadratic) model is commonly used in response surface methodology, as follows [22-24]:

$$
\begin{aligned}
Y= & \beta_{0}+\sum_{i=1}^{k} \beta_{i} X_{i}+\sum_{i=1}^{k} \beta_{i i} X_{i i}^{2} \\
& +\sum_{i<j} \beta_{i j} X_{i} X_{j}+e\left(X_{1}, X_{2} \ldots X_{k}\right) .
\end{aligned}
$$

In this study, the value of $a$ is 2 , and 21 experiments were designed for each adsorbent using RSM. The level and range of parameter changes are indicated in Table 1.

Erlenmeyer flasks of $250 \mathrm{~mL}$ were used for experiments, and the temperature was fixed at $25^{\circ}$. After a precise measuring of the amount of adsorbent by the weighing scale, the solutions were made at the required concentration using the dilution method. Before performing each experiment, the $\mathrm{pH}$ of the solutions was adjusted using 0.1 molar nitric acid and sodium hydroxide solutions. After adjusting the $\mathrm{pH}, 50 \mathrm{~mL}$ of the lead solution was poured into closed Erlenmeyer flasks, and a certain amount of adsorbent was added before placing it on the shaker at $120 \mathrm{rpm}$ for specified times. After mixing the solutions and the adsorbent, the Erlenmeyer flasks were centrifuged for $15 \mathrm{~min}$ at $3,500 \mathrm{rpm}$, at which point the initial separation of the adsorbent from the solution occurs, and the solution was passed through a $0.45-\mathrm{mi}$ cron filter paper. Finally, the concentration of lead was measured by a flame atomic absorption spectrophotometer (AAS-240).

2.4. Calculation of the Amount of Adsorbent Lead, Isotherms, and Adsorption Kinetics. The following equations, which are in units of $\mathrm{mg} / \mathrm{g}$ and percentage, were used to calculate the amount of lead adsorbed and the percentage of adsorbed lead, respectively.

$$
\begin{aligned}
q & =\frac{V\left(C_{i-} C_{e}\right)}{m}, \\
\operatorname{Removal}(\%) & =\frac{C_{i}-C_{e}}{C_{i}} \times 100,
\end{aligned}
$$

where $q$ and $V$ are the amount of lead absorbed by the adsorbents in $\mathrm{mg} / \mathrm{g}$ and the volume of solution in liters, respectively; $C_{i}$ and $C_{e}$ account for initial and equilibrium concentration in $\mathrm{mg} / \mathrm{l}$, respectively, and $m$ is the amount of dose of adsorbent (gr). Finally, after calculating the experimental results, three isotherms, namely, Freundlich, Langmuir, and D-R, and three kinetic models, namely, pseudo-second-order, pseudo-first-order, and zero-order kinetic models were determined for adsorbents.

\subsection{Adsorption Isotherms Studies}

2.5.1. Langmuir Isotherm. The Langmuir isotherm is one of the most commonly used equations of adsorption isotherms that at first was used to investigate the adsorption of gases on the solid surface and was then applied to the adsorption of substances in solutions.

Langmuir isotherm can be expressed in the following equation, in which $\mathrm{Ce}$ is responsible for the concentration of ions in solution $(\mathrm{mg} / \mathrm{L})$ and $b$ constant is obtained by dividing the equilibrium constant of the absorption reaction to the equilibrium constant of the desorption reaction $\left(K_{a} / K_{d}\right)$ [28]. 
TABLE 1: Level and range of parameter changes.

\begin{tabular}{lccccc}
\hline \multirow{2}{*}{ Variables } & \multicolumn{5}{c}{ Level and range of changes } \\
& $+\propto$ & 1 & 0 & -1 & $-\propto$ \\
\hline $\mathrm{pH}$ & 2 & 3.5 & 5 & 6.5 & 8 \\
Time (min) & 15 & 45 & 15 & 105 & 135 \\
$\mathrm{~Pb}(\mathrm{II})$ conc $(\mathrm{mg} / \mathrm{L})$ & 10 & 45 & 80 & 115 & 150 \\
Adsorbent dose (g/L) & 5 & 15 & 25 & 35 & 45 \\
\hline
\end{tabular}

$$
\theta=\frac{b C_{e}}{1+b C_{e}} .
$$

If the parameter $\theta$ is defined as $\theta=q_{e} / q_{\max }$, where $q_{\max }$ and $q_{e}$ are the maximum amount of material adsorbed in $(\mathrm{mg} / \mathrm{g})$ and the amount of sites that are actually occupied by the adsorbent at the concentration of $C_{e}(\mathrm{mg} / \mathrm{g})$, respectively. So the linear form of the Langmuir isotherm is defined as follows:

$$
\frac{C_{e}}{q_{c}}=\frac{1}{b q_{\max }}+\frac{C_{e}}{q_{\max }} .
$$

In order to further analyze the Langmuir isotherm, the dimensionless parameter $R_{L}$, which is known as separation coefficient, can be defined as follows:

$$
R_{L}=\frac{1}{1+b C_{0}}
$$

where $C_{0}$ is the initial concentration of the absorbent in the solution $(\mathrm{mg} / \mathrm{L})$. If this parameter is between 0 and 1 $\left(0 R_{L}<1\right)$, the Langmuir isotherm is desirable, and if this parameter is greater than $1\left(1 R_{L}\right)$ the isotherm is undesirable $[29,30]$.

2.5.2. Freundlich Isotherm. The Freundlich isotherm, which is represented in the following equation, has been obtained by the assumption of multilayer adsorption on the heterogeneous sites with unequal and dissimilar energies:

$$
q_{e}=k_{f} C_{e}^{(1 / n)} \text {, }
$$

where $k_{f}$ and $n$ are Freundlich's constants that are known as the adsorption capacity and the adsorption intensity, respectively. The linear form of the Freundlich isotherm is shown in the following equation [31]:

$$
\ln q_{e}=\ln k_{f}+\frac{1}{n} \ln C_{e} .
$$

By Plotting $\operatorname{Ln}\left(q_{e}\right)$ in $\operatorname{Ln}\left(C_{e}\right)$ and using the laboratory data, the slope of the obtained line from the linear fitting of these data represents the value of $1 / n$, and the intercept equals the value of $\operatorname{Ln}\left(k_{f}\right)$. Increasing the constant $K_{f}$ results in increasing the adsorption capacity of the adsorbents, and when the constant $n$ is between 1 and 13, it indicates that the adsorption process is appropriate. However, while the constant $n$ is approaching 1 , it means that the heterogeneity of the adsorbents' surface has a low importance, and when approaching 10, it means that the heterogeneity of the adsorbent surface increases [31, 32].
2.5.3. D-R (Dubinin-Radushevich) Isotherm. This isotherm is like the Freundlich isotherm, based on the assumption of adsorption on a heterogeneous surface and often used to characterize the process, physical or chemical adsorption process, by calculating the $E$ parameter, known as the average free energy of absorption $(\mathrm{kJ} / \mathrm{mol})$, if this parameter is less than $8 \mathrm{~kJ} / \mathrm{mol}(E<8 \mathrm{~kJ} / \mathrm{mol})$, it means that the physical absorption process is dominant, and if $16 \mathrm{~kJ} / \mathrm{mol}>E>8 \mathrm{~kJ} /$ mol, the chemical adsorption process is dominated by ion exchange [33, 34]. The following equations represent the linear equation of the parameter $\mathrm{E}$ and the $\mathrm{D}-\mathrm{R}$ isotherm, respectively.

$$
\begin{aligned}
E & =\frac{1}{\sqrt{2 k_{\mathrm{DR}}}}, \\
\ln q_{e} & =\ln q_{\max }-k_{\mathrm{DR}^{\varepsilon^{2}}},
\end{aligned}
$$

where $q_{\max }$ accounts for the maximum amount of adsorbed material under the present conditions $(\mathrm{mg} / \mathrm{g}), q_{e}$ is responsible for the amount of ions adsorbed to the substance that is actually absorbed at the concentration of $C_{e}(\mathrm{mg} / \mathrm{g})$. the $\mathrm{kDR}$ is a constant that corresponds to the average free energy during the adsorption process $\left(\mathrm{mol}^{2} / \mathrm{J}^{2}\right)$, and the parameter $\varepsilon$ is also obtained from the following equation [34]:

$$
\varepsilon=R T \ln \left(1+\frac{1}{C_{e}}\right)
$$

2.5.4. Adsorption Kinetics. Adsorption kinetics are the main factors for designing adsorption systems in the prediction of the rate of adsorption process controlled. The adsorption kinetics depends on the physical and chemical properties of the adsorbent, which affect the adsorption mechanism. To investigate the adsorption mechanism, the adsorption constants can be calculated using the pseudo-second-order kinetics equation $[35,36]$, the pseudo-first-order kinetics equation [37], and the zero-order kinetics equation [38]. The linear form of the pseudo-first-order equation is given in the following equation:

$$
\log \left(q_{e}-q_{t}\right)=\log q_{e}-\frac{k_{1}}{2.303} t
$$

where $q, q_{t}$, and $k_{1}$ are the amount of absorbed substance at equilibrium $(\mathrm{mg} / \mathrm{g})$, absorbed substance at the moment of $t$ $(\mathrm{mg} / \mathrm{g})$, and a constant of the equilibrium rate of the pseudofirst-order absorption $\left(\mathrm{min}^{-1}\right)$, respectively. If the log $\left(q_{e}-q_{t}\right)$ is plotted in terms of $t$ for the experimental conditions, a straight line can be obtained that the $k_{1}$ and the $R^{2}$ correlation coefficient can be determined from its graph [39]. Also, the linear form of the pseudo-second-order equation is expressed as follows:

$$
\frac{t}{q_{t}}=\frac{1}{k_{2} q_{e}^{2}}+\frac{1}{q_{e}} t
$$

where $q, q_{t}$, and $k_{2}$ are the amount of absorbed substance at equilibrium ( $\mathrm{mg} / \mathrm{g})$, the amount of absorbed substance at the 
moment of $t(\mathrm{mg} / \mathrm{g})$, and a constant of the equilibrium rate of the pseudo-second-order absorption (g/mg.min), respectively. By plotting the $t / q_{t}$ in terms of $t$, that the $k_{2}$ and the $R^{2}$ correlation coefficient can be determined from its graph [40]. Also, the linear form of the zero-order equation is expressed as follows:

$$
q_{i}=\frac{1}{\beta} \ln (\alpha \beta)+\frac{1}{\beta} \ln (t),
$$

where $q_{i}$ accounts for the amount of absorbed substance at the moment of $t(\mathrm{mg} / \mathrm{g}), a$ and $\beta$ are also reported as the initial adsorption rate (g/mg.min) and the desorption constant (g/mg), respectively [33].

\section{Results and Discussion}

The results are represented as lead removal percentage along with experimental designs for both adsorbents MG and TT in Table 2. Estimated models using Design Expert 7.0 software for both MG and TT are quadratic as mentioned below:

$$
\begin{aligned}
\% R(\text { MG powder })= & -130.36+46.01 \mathrm{pH}+0.88 \text { Time } \\
& -0.22 \mathrm{Conc} \mathrm{Pb}+3.34 \mathrm{Dos}-3.74 \mathrm{pH}^{2} \\
& -4.87^{0.003} \mathrm{Time}^{2}-0.05 \mathrm{Dose}^{2}, \\
\% R(\text { TT powder })= & -135.72+46 \mathrm{pH}+0.76 \text { Time } \\
& +0.07 \mathrm{Conc} \mathrm{Pb}+3.75 \mathrm{Dose}-3.75 \mathrm{pH}^{2} \\
& -4.53^{0.003} \mathrm{Time}^{2}-2.08^{0.003} \mathrm{Conc}^{2} \\
& -0.06 \mathrm{Dose}^{2} .
\end{aligned}
$$

3.1. Statistical Analysis of Models and Results of Experimental Design. The statistical results of the chosen model according to RSM for adsorbents are shown in Table 3, and both adsorbent models are significant with a $P$ value of less than 0.0001 . Based on Figures 3 and 4, which the perturbation diagram is shown, despite the three parameters, namely, $\mathrm{pH}$, dose of adsorbent, and initial lead concentration in solution, which had the most effect on adsorption because of their further gradient, the time of contact had the least influence. In addition, the negative gradient of initial lead concentration in solution means that the percentage of adsorption decreases as the initial lead concentration rises.

3.2. The Effects of pH on the Lead Adsorption. According to Figures 3 and 4, the adsorption process of lead increases as the media transfers from acidic to alkaline, and the rate of adsorption is the highest in the range of $\mathrm{pH}$ between 5.5 and 6.5 , which is in accordance with the result of Hashem in investigating the lead adsorption from aqueous solution by okra waste [33].

The competition between metal cations such as $\mathrm{H}^{+}$and $\mathrm{H}_{3} \mathrm{O}^{+}$ions in soluble form is the main reason for low adsorption at low $\mathrm{pH}$. Hence, the adsorption of $\mathrm{H}^{+}$and $\mathrm{H}_{3} \mathrm{O}^{+}$ ions on the surface of the adsorbent prevents the maximum adsorption of metal cations [40,41]. As the $\mathrm{pH}$ increases and the acidity decreases, the competition disappears, and the cations get the highest sorption. The main reason for limiting the optimization experiment to the $\mathrm{pH}$ below 8 is that for the $\mathrm{pH}$ up to 8 , the lead in the solution is precipitated as hydroxide compounds and escapes the solution [42].

3.3. The Effects of Time of Contact on the Lead Adsorption. According to Figures 3 and 4, the procedure of adsorption increases at the initial times $(0 T<15 \mathrm{~min})$ due to the vacancy of adsorption sites on the adsorbent surface. As time passes, the rate of adsorption increases more slowly and gradually the maximum rate of adsorption followed by a plateau. Moreover, for both MG and TT, by passing the $135 \mathrm{~min}$, the adsorption rate follows a reverse trend and decreases owing to the fact that adsorbents enter the desorption phase. The optimum time of contact for MG and TT powder is between 65 and 90 and 55 and 85, respectively.

3.4. The Effects of Dose of Adsorbent on Lead Adsorption. As expected, according to Figures 3 and 4 , as the proportion of dose of adsorbent in the solution volume rises, the proportion of lead adsorption increases for the rising of adsorption sites on the surface of the adsorbent. The optimum ratio for both adsorbents is between 25 and $35 \mathrm{~g}$ of adsorbent per liter of solution. It should be considered that increasing the dose of adsorbent can cause rising in the lead adsorption to a certain extent (until the adsorbed lead is adsorbed in the solution), and after that, the ratio of the adsorbed lead to the total dose of adsorbent is dropped, so the adsorption capacity follows an opposite trend.

\subsection{The Effects of Initial Concentration of Lead on Adsorption}

Process. As the initial concentration of lead decreases, the proportion of lead adsorption goes up. More the concentration of metal cations in the solution, the higher the number of susceptible cations in the solution; however, the sites on the surface of adsorbents will be limited. The effects of the initial concentration of lead on the lead adsorption by MG and TT powder are shown in Figures 3 and 4, respectively. Based on the optimization results, the optimum adsorption conditions for MG and TT powder are presented in Table 4.

3.6. Results of Adsorption Isotherms. The results for the Langmuir, Freundlich, and D-R isotherms according to equations (3)-(11), for the adsorption process, are shown in Figures 5-10. Also, the constant for each isotherm for MG and TT powder are illustrated in Tables 5 and 6, respectively. Consequently, on the one hand, the adsorption process of MG powder follows the Langmuir isotherm, which indicates the multilayer adsorption of heterogeneous adsorption sites and unequal adsorption energy, and the adsorption process of TT powder pursues the D-R isotherm, and according to equations (9) and (10), the average adsorbed energy for TT powder is $1.12 \mathrm{~kJ} / \mathrm{mol}$; therefore, the adsorption process is physical and multilayer. 
TABLE 2: Designed experiments and lead removal percentage for adsorbents.

\begin{tabular}{|c|c|c|c|c|c|c|}
\hline Run & $\mathrm{pH}$ & Time $(\min )$ & $\mathrm{Pb}(\mathrm{II})$ conc $(\mathrm{mg} / \mathrm{l})$ & Adsorbent dose $(\mathrm{g} / \mathrm{l})$ & $\%$ Removal of MG & $\%$ Removal of TT \\
\hline 1 & 3.5 & 105 & 45 & 35 & 58.35 & 57.59 \\
\hline 2 & 8 & 75 & 80 & 25 & 75.15 & 75.13 \\
\hline 3 & 3.5 & 105 & 115 & 35 & 48.35 & 43.35 \\
\hline 4 & 3.5 & 45 & 45 & 15 & 36.59 & 41.25 \\
\hline 5 & 5 & 75 & 80 & 25 & 83.5 & 80.5 \\
\hline 6 & 5 & 75 & 80 & 25 & 85 & 81.25 \\
\hline 7 & 5 & 75 & 150 & 25 & 61.89 & 56.69 \\
\hline 8 & 5 & 75 & 80 & 25 & 81.64 & 81.64 \\
\hline 9 & 6.5 & 45 & 115 & 35 & 65.66 & 64.66 \\
\hline 10 & 5 & 135 & 80 & 25 & 80.45 & 74.13 \\
\hline 11 & 5 & 75 & 10 & 25 & 95.25 & 93.50 \\
\hline 12 & 3.5 & 45 & 115 & 15 & 23.19 & 25.70 \\
\hline 13 & 5 & 75 & 80 & 45 & 84.25 & 79.10 \\
\hline 14 & 6.5 & 45 & 45 & 35 & 87.19 & 82.43 \\
\hline 15 & 6.5 & 105 & 45 & 15 & 70.55 & 77.45 \\
\hline 16 & 5 & 75 & 80 & 25 & 83.56 & 80.98 \\
\hline 17 & 2 & 75 & 80 & 25 & 29.98 & 27.95 \\
\hline 18 & 6.5 & 105 & 115 & 15 & 59.86 & 53.45 \\
\hline 19 & 5 & 75 & 80 & 25 & 81.95 & 80.76 \\
\hline 20 & 5 & 15 & 80 & 25 & 56.89 & 63.78 \\
\hline 21 & 5 & 75 & 80 & 5 & 48.76 & 43.53 \\
\hline
\end{tabular}

TABLe 3: Statistical results of the selected models using RSM for adsorbents.

\begin{tabular}{rccccrr}
\hline Model & & $P$ value & Std. dev & \% CV & $R^{2}$ & Adj. $R^{2}$ \\
\hline \multirow{2}{*}{ \% Removal quadratic model } & MG powder & $<0.0001$ & 6.40 & 8.11 & 0.945 & 0.922 \\
& TT powder & $<0.0001$ & 4.93 & 7.66 & 0.961 & 0.935 \\
\hline
\end{tabular}

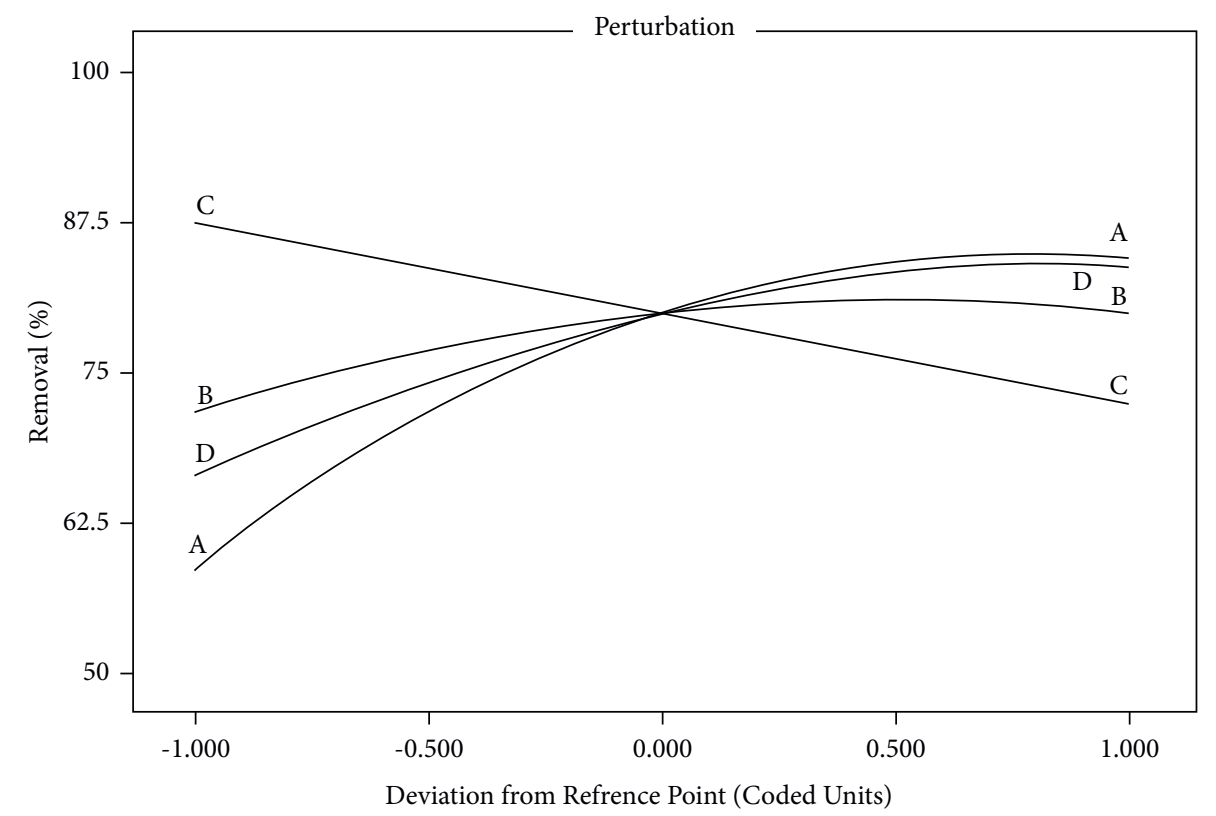
A: $\mathrm{pH}(5)$
C: Conc $\mathrm{Pb}(80, \mathrm{mg} / 1)$
B: Time $(15, \min )$
D: Dose $(25, \mathrm{~g} / 1)$

FIgURE 3: Parameters perturbation for MG powder.

3.7. Results of Adsorption Kinetics. The results for the pseudo-first-order, pseudo-second-order, and zero-order kinetics according to the equations (12)-(14) for the adsorption process are shown in Figures 11-16. Also, the constants for each kinetic and correlation coefficient for MG and TT powder are represented in Tables 7 and 8, 


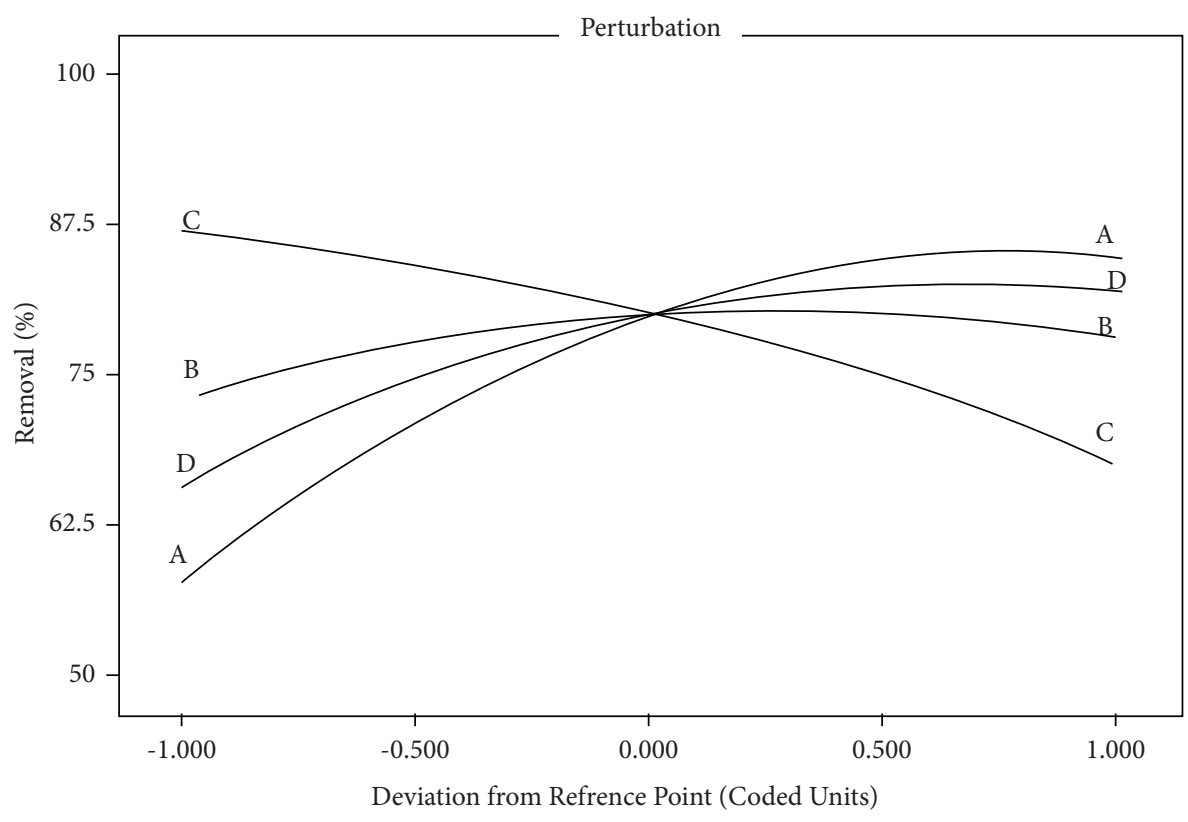
A: $\mathrm{pH}(5)$
$\mathrm{C}:$ Conc $\mathrm{Pb}(80, \mathrm{mg} / 1)$
B: Time $(15, \mathrm{~min})$
D: Dose $(25, g / 1)$

Figure 4: Parameters perturbation for TT powder.

TABLE 4: Software optimized points for adsorbents.

\begin{tabular}{lcccccc}
\hline Adsorbent & Solution number & $\mathrm{pH}$ & Time & $\mathrm{Pb}(\mathrm{II})$ conc & Adsorbent dose & \% Removal \\
\hline \multirow{3}{*}{ MG powder } & 1 & 5.97 & 71.37 & 45.97 & 25.46 & 92.15 \\
& 2 & 5.61 & 62.08 & 49.14 & 33.20 & 91.83 \\
& 3 & 5.89 & 96.94 & 45.08 & 24.90 & 93.25 \\
\hline \multirow{3}{*}{ TT powder } & 1 & 6 & 58.91 & 45.35 & 52.93 & 29.86 \\
& 2 & 5.86 & 62.02 & 56.56 & 27.07 & 91.54 \\
\end{tabular}

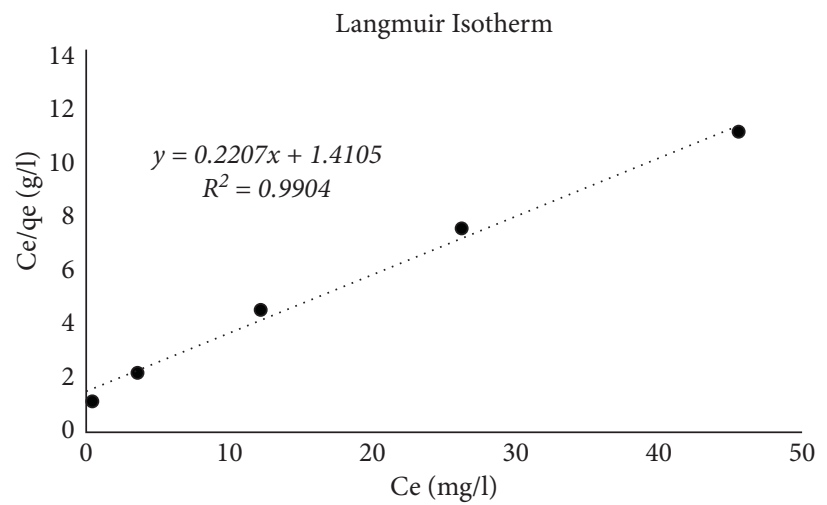

Figure 5: $C_{e} / q_{e}$ variations to $C_{e}$, Langmuir isotherm, MG powder.

respectively. Both adsorbents with $R^{2}$ about 0.99 follow the pseudo-second-order adsorption kinetics. Furthermore, both MG and TT with high correlation coefficients (90\% and 92\%) follow the pseudo-first-order adsorption kinetics.
Environmental pollution with toxic metals is one of the results of human activities such as mining and metallurgy. The harmful effects of these metals on plant and animal ecosystems and public health are important. Biosorbents 


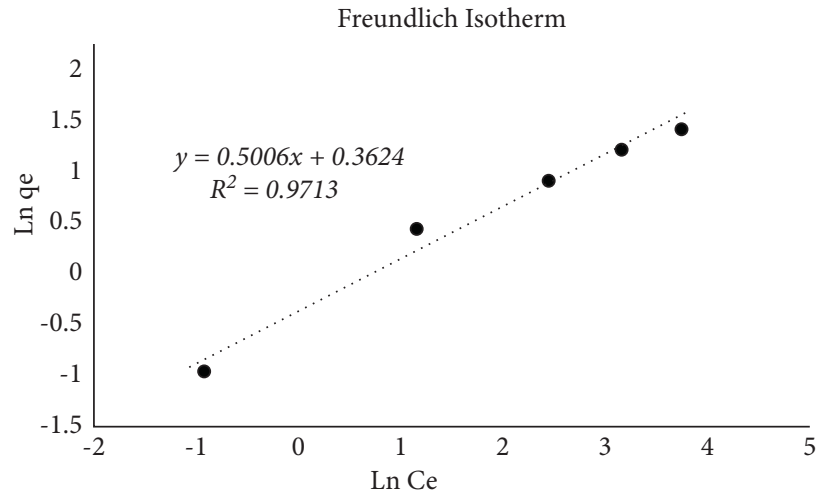

Figure 6: $\operatorname{Ln}\left(q_{e}\right)$ variations to $\operatorname{Ln}\left(C_{e}\right)$, Freundlich isotherm, MG powder.

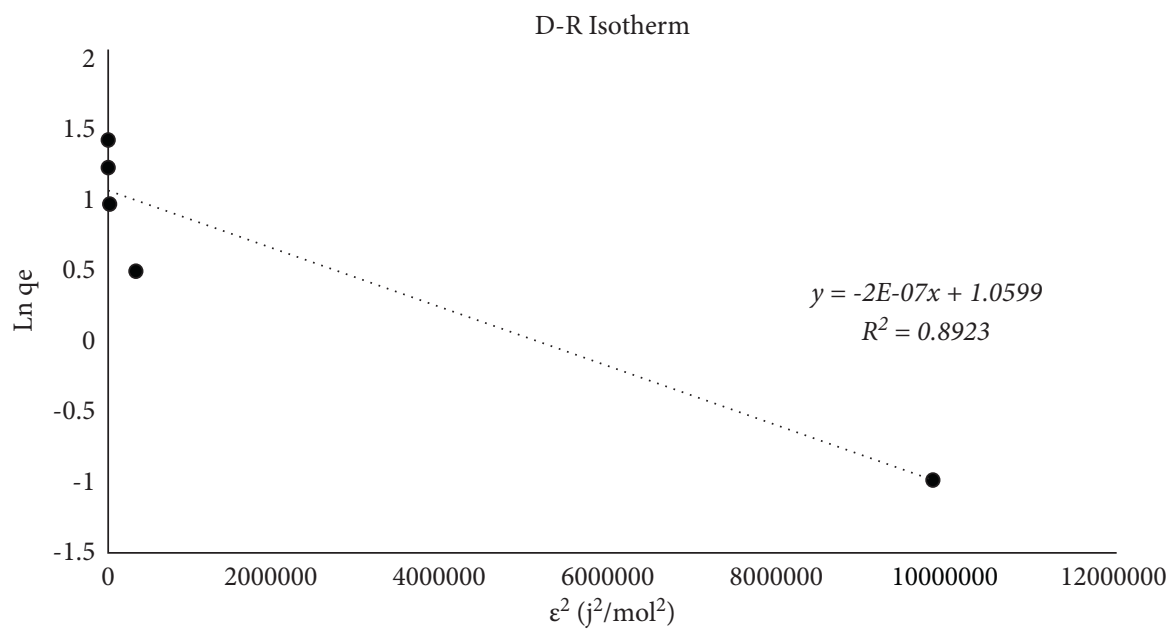

Figure 7: $\operatorname{Ln}\left(q_{e}\right)$ to $\varepsilon^{2}, \mathrm{D}-\mathrm{R}$ isotherm, MG powder.

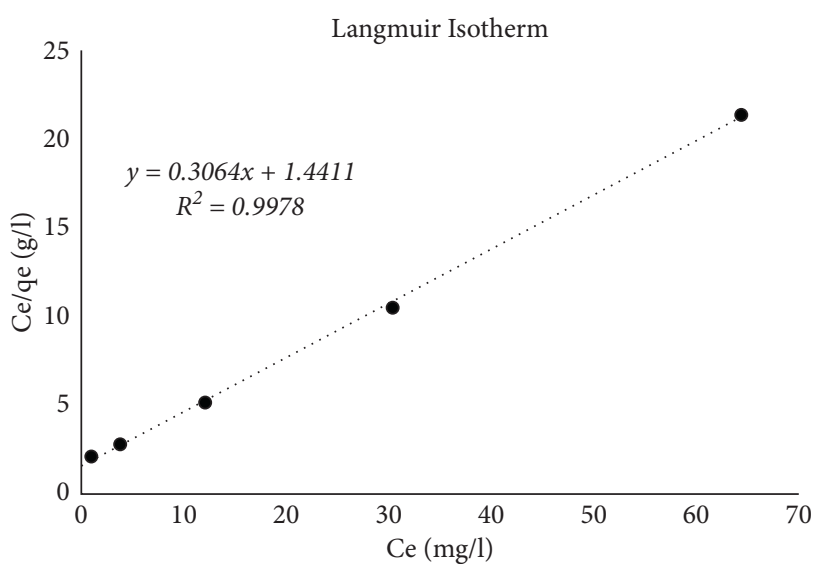

Figure 8: $C_{e} / q_{e}$ variations to $C_{e}$, Langmuir isotherm, TT powder.

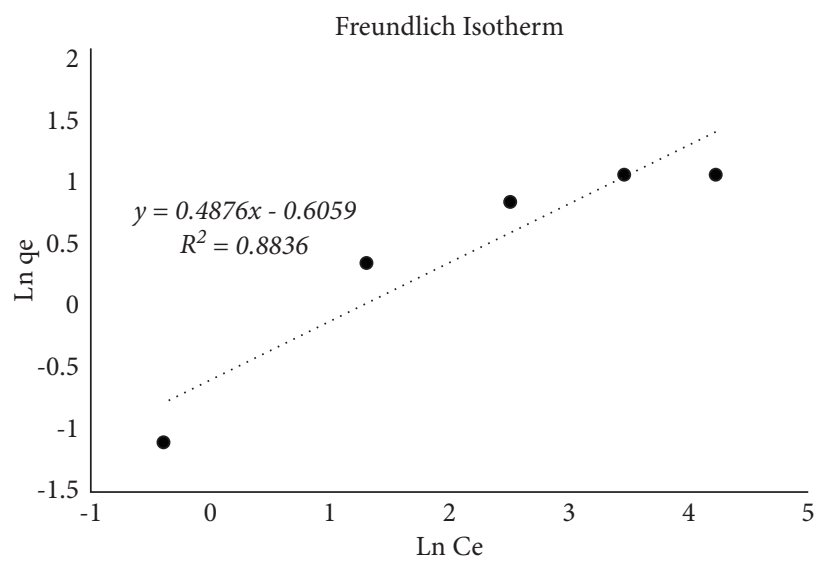

Figure 9: $\operatorname{Ln}\left(q_{e}\right)$ variations to $\operatorname{Ln}\left(C_{e}\right)$, Freundlich isotherm, TT powder. 


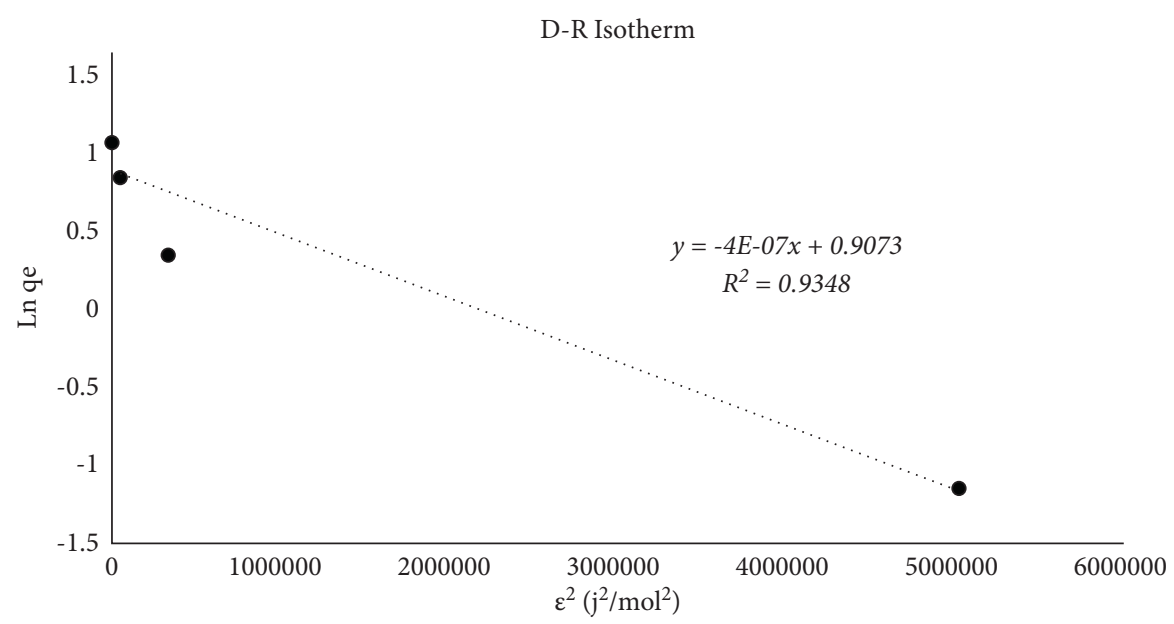

Figure 10: $\operatorname{Ln}\left(q_{e}\right)$ to $\varepsilon^{2}$, D-R isotherm, TT powder.

TABle 5: Constants of adsorption isotherms determined for MG powder.

\begin{tabular}{lccccccccc}
\hline & \multicolumn{2}{c}{ D-R isotherm } & \multicolumn{3}{c}{ Freundlich isotherm } & \multicolumn{2}{c}{ Langmuir isotherm } \\
\hline$R^{2}$ & $K_{\mathrm{DR}}\left(\mathrm{J}^{2} / \mathrm{mol}^{2}\right)$ & $q_{\max }(\mathrm{mg} / \mathrm{g})$ & $R^{2}$ & $N$ & $k_{f}\left((\mathrm{mg} / \mathrm{g}) /(\mathrm{mg} / \mathrm{L})^{n}\right)$ & $R^{2}$ & $\mathrm{~B}(\mathrm{~L} / \mathrm{mg})$ & $q_{\max }(\mathrm{mg} / \mathrm{g})$ & $q_{\mathrm{mpre}}(\mathrm{mg} / \mathrm{g})$ \\
0.89 & 0.0000002 & 2.886 & 0.9713 & 1.998 & 0.696 & 0.9904 & 0.157 & 4.53 & 1.7 \\
\hline
\end{tabular}

TABLE 6: Constants of adsorption isotherms determined for TT powder.

\begin{tabular}{lccccccccc}
\hline & D-R isotherm & \multicolumn{3}{c}{ Freundlich isotherm } & \multicolumn{2}{c}{ Langmuir isotherm } \\
\hline$R^{2}$ & $K_{D R}\left(\mathrm{~J}^{2} / \mathrm{mol}^{2}\right)$ & $q_{\max }(\mathrm{mg} / \mathrm{g})$ & $R^{2}$ & $N$ & $k_{f}\left((\mathrm{mg} / \mathrm{g}) /(\mathrm{mg} / \mathrm{L})^{n}\right)$ & $R^{2}$ & $\mathrm{~B}(\mathrm{~L} / \mathrm{mg})$ & $q_{\max }(\mathrm{mg} / \mathrm{g})$ & $q_{\mathrm{mpre}}(\mathrm{mg} / \mathrm{g})$ \\
0.935 & 0.0000004 & 2.478 & 0.884 & 2.051 & 0.546 & 0.9978 & 0.213 & 3.26 & 1.5 \\
\hline
\end{tabular}

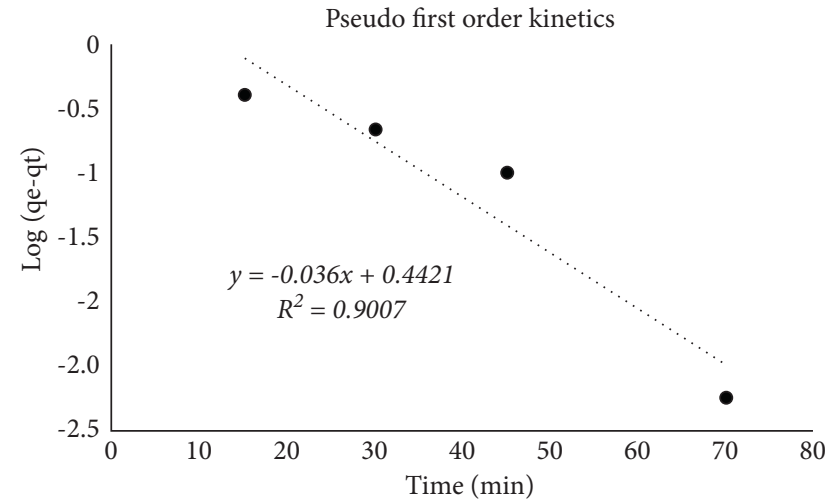

FIgURe 11: Pseudo-first-order kinetic for MG powder.

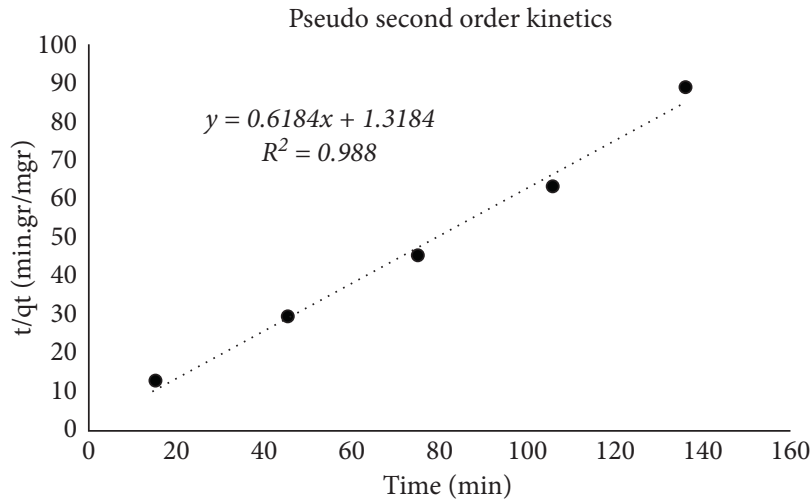

FIgURe 12: Pseudo-second-order kinetic for MG powder. 


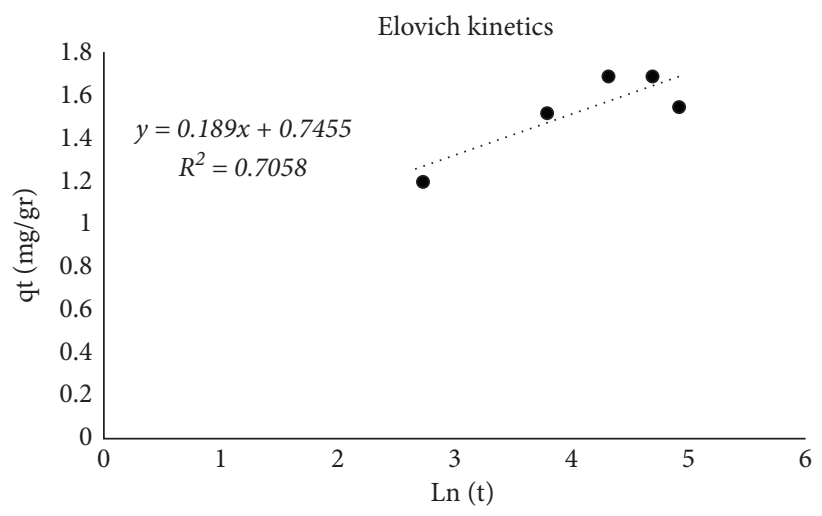

Figure 13: Zero-order kinetics for MG powder.

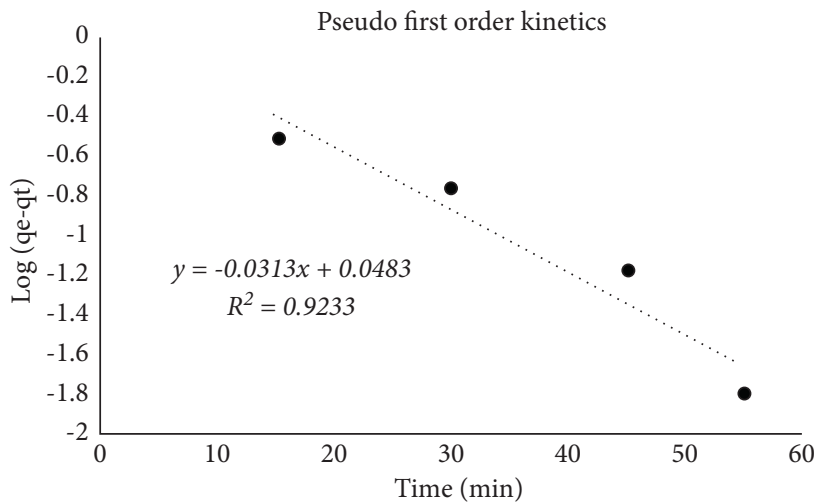

Figure 14: Pseudo-first-order kinetic for TT powder.

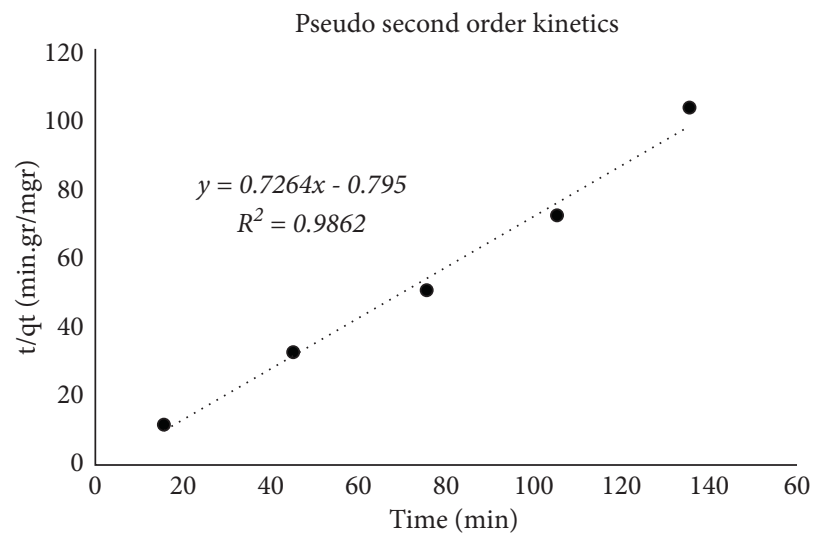

FIgURE 15: Pseudo-second-order kinetic for TT powder. 


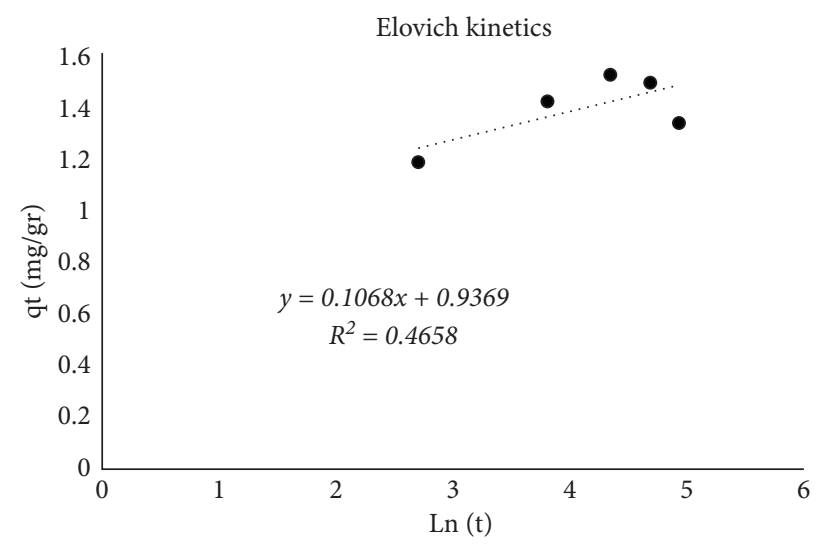

Figure 16: Zero-order kinetics for TT powder.

TABLe 7: Adsorption kinetic constants for MG powder.

\begin{tabular}{|c|c|c|c|c|c|c|c|c|c|}
\hline \multicolumn{3}{|c|}{ Zero-order kinetic } & \multicolumn{3}{|c|}{ Pseudo-second-order kinetic } & \multicolumn{4}{|c|}{ Pseudo-first-order kinetic } \\
\hline$R^{2}$ & $\alpha$ (g/mg.min) & $\beta(\mathrm{g} / \mathrm{mg})$ & $R^{2}$ & $K_{2}$ (g/mg.min) & $q_{e}(\mathrm{mg} / \mathrm{g})$ & $R^{2}$ & $K_{1}\left(\min ^{-1}\right)$ & $q_{e}(\mathrm{mg} / \mathrm{g})$ & $q_{e}$ pre $(\mathrm{mg} / \mathrm{g})$ \\
\hline 0.706 & 9.761 & 5.291 & 0.988 & 0.290 & 1.617 & 0.90 & 0.083 & 2.768 & 1.664 \\
\hline
\end{tabular}

TABle 8: Adsorption kinetic constants for TT powder.

\begin{tabular}{|c|c|c|c|c|c|c|c|c|c|}
\hline \multicolumn{3}{|c|}{ Zero-order kinetic } & \multicolumn{3}{|c|}{ Pseudo-second-order kinetic } & \multicolumn{4}{|c|}{ Pseudo-first-order kinetic } \\
\hline$R^{2}$ & $\alpha$ (g/mg.min) & $\beta(\mathrm{g} / \mathrm{mg})$ & $R^{2}$ & $K_{2}$ (g/mg.min) & $q_{e}(\mathrm{mg} / \mathrm{g})$ & $R^{2}$ & $K_{1}\left(\min ^{-1}\right)$ & $q_{e}(\mathrm{mg} / \mathrm{g})$ & $q_{e}$ pre $(\mathrm{mg} / \mathrm{g})$ \\
\hline 0.466 & 689.54 & 9.36 & 0.986 & 0.664 & 1.377 & 0.923 & 0.072 & 1.118 & 1.463 \\
\hline
\end{tabular}

help accelerate the removal of concentrations of residual contaminants in the environment $[43,44]$.

\section{Conclusion}

The purpose of this study was to investigate the effects of biosorbents, Mespilus germanica and Tribulus terrestris powder, on the removal of lead from aqueous solutions. Both biosorbents had a great capability in lead adsorption. The CCD under RSM is designed based on the fit of the tentative model to the experimental data. In the optimum conditions with the initial lead concentration of $10 \mathrm{mg} / \mathrm{l}, \mathrm{MG}$ powder had better performance in lead adsorption of 96.04\%, and TT powder also had an acceptive performance of $93.20 \%$. Furthermore, the optimum condition for the MG powder includes $\mathrm{pH}$ of 5.97, time of contact of $71 \mathrm{~min}$, and dose of adsorbent to solution volume of $25.5 \mathrm{~g} / \mathrm{l}$. The adsorption procedure of MG powder follows the Freundlich isotherm with a correlation coefficient of 0.971 , and the D-R isotherm is also accepted by the correlation coefficient of 0.892 . It also follows the pseudo-second-order and pseudofirst-order kinetic with a correlation coefficient of 0.988 and 0.90 , respectively. On the other hand, the optimum condition for the TT powder comprises $\mathrm{pH}$ of 6 , time of contact of $59 \mathrm{~min}$, and dose of adsorbent to solution volume of $28.4 \mathrm{~g} / \mathrm{l}$. The adsorption procedure of TT powder pursues the $\mathrm{D}-\mathrm{R}$ isotherm with a correlation coefficient of 0.935 , though matching this process with the Freundlich isotherm is also acceptable with the correlation coefficient of 0.884 . This process with correlation coefficients of 0.986 and 0.932 follows the pseudo-second-order and pseudo-first-order, respectively. Finally, the adsorption procedure for both adsorbents is physical and multilayer.

\section{Data Availability}

The data used to support the findings of this study are included within the article.

\section{Conflicts of Interest}

The authors declare that they have no conflicts of interest or personal relationships that could have appeared to influence the work reported in this paper.

\section{Acknowledgments}

The authors gratefully acknowledge the support provided from K.N. Toosi University of Technology authorities and staff, especially environmental engineering laboratory management.

\section{References}

[1] M. Salari, E. S. Salami, S. H. Afzali et al., "Quality assessment and artificial neural networks modeling for characterization of chemical and physical parameters of potable water," Food and Chemical Toxicology, vol. 118, pp. 212-219, 2018.

[2] E. S. Salami, M. Salari, M. Ehteshami, N. T. Bidokhti, and H. Ghadimi, "Application of artificial neural networks and mathematical modeling for the prediction of water quality 
variables (case study: southwest of Iran)," Desalination and Water Treatment, vol. 57, no. 56, pp. 27073-27084, 2016.

[3] E. S. Salami, M. Salari, S. S. Nikbakht, M. HosseiniKheirabad, and E. Teymouri, "Dataset on the assessments the rate of changing of dissolved oxygen and temperature of surface water, case study: California, USA," Journal of Environmental Treatment Techniques, vol. 7, no. 3, pp. 843-852, 2020.

[4] M. Salari, E. Teymouri, and Z. Nassaj, "Application of an artificial neural network model for estimating of water quality parameters in the karun river, Iran," Journal of Environmental Treatment Techniques, vol. 9, no. 4, pp. 720-727, 2021.

[5] J. O. Duruibe, M. O. Ogwuegbu, and J. N. Egwurugwu, "Heavy metal pollution and human biotoxic effects," International Journal of Physical Sciences, vol. 2, no. 5, pp. 112-118, 2007.

[6] I. Oboh, E. Aluyor, and T. Audu, "Biosorption of heavy metal ions from aqueous solutions using a biomaterial," Leonardo Journal of Sciences, no. 14, pp. 58-65, 2009.

[7] World Health Organization, Drinking Water Standards and Health Advisories Office of Water, US Environmental Protection Agency Washington, Washington, USA, 2011.

[8] "WHO guidline for drinking water quality," in Recommendations, World Health OrganizationVol. 1, WHO, Geneva, 2004.

[9] F. Veglio and F. Beolchini, "Removal of metals by biosorption: a review," Hydrometallurgy, vol. 44, no. 3, pp. 301-316, 1997.

[10] S. Shamim, "Biosorption of heavy metals," Biosorption, vol. 2, pp. 21-49, 2018.

[11] E. J. Terán, M. L. Montes, C. Rodríguez et al., “Assessment of sorption capability of montmorillonite clay for lead removal from water using laser-induced breakdown spectroscopy and atomic absorption spectroscopy," Microchemical Journal, vol. 144, pp. 159-165, 2019.

[12] S. A. Mousavi, A. Almasi, F. Navazeshkh, and F. Falahi, "Biosorption of lead from aqueous solutions by algae biomass: optimization and modeling," Desalination and Water Treatment, vol. 148, pp. 229-237, 2019.

[13] Y. Li, S. Song, L. Xia et al., "Enhanced $\mathrm{Pb}$ (II) removal by algalbased biosorbent cultivated in high-phosphorus cultures," Chemical Engineering Journal, vol. 361, pp. 167-179, 2019.

[14] P. Salehi, B. Asghari, and F. Mohammadi, "Biosorption of $\mathrm{Ni}(\mathrm{II}), \mathrm{Cu}(\mathrm{II})$ and $\mathrm{Pb}$ (II) by punica gerana-tum from aqueous solutions," Journal of Water Resource and Protection, vol. 02, no. 8, pp. 701-705, 2010.

[15] L. Joseph, B.-M. Jun, J. R. V. Flora, C. M. Park, and Y. Yoon, "Removal of heavy metals from water sources in the developing world using low-cost materials: a review," Chemosphere, vol. 229, pp. 142-159, 2019.

[16] E. Teymouri, S. F. Mousavi, H. Karami, M. S. Farzin, and H. Kheirabad, "Reducing urban runoff pollution using porous concrete containing mineral adsorbents," Journal of Environmental Treatment Techniques, vol. 8, no. 1, pp. 429-436, 2020.

[17] H. Karami, E. Teymouri, S. F. Mousavi, and S. Farzin, "Experimental investigation of the effect of adding LECA and Pumice on some physical properties of porous concrete, applicable in urban runoff system," International Journal of Engineering, vol. 22, no. 1, pp. 0125-8281, 2018.

[18] E. Teymouri, S. F. Mousavi, H. Karami, S. Farzin, and M. H. Kheirabad, "Municipal Wastewater pretreatment using porous concrete containing fine-grained mineral adsorbents," Journal of Water Process Engineering, vol. 36, pp. 101-346, 2020.

[19] I. H. Kalyoncu, N. Ersoy, A. Y. Elidemir, and I. Tolay, "Some physico-chemical and nutritional properties of Musmula'Medlar (Mespilus germanica L.) grown in northeast anatolia," The World Academy of Science, Engineering and Technology International Journal of Agricultural and Biosystems Engineering, vol. 7, no. 6, 2013.

[20] T. S. Wu, L. S. Shi, and S. C. Kuo, "Alkaloids and other constituents from Tribulus terrestris," Phytochemistry, vol. 50, no. 8, pp. 1411-1415, 1999.

[21] G. R. Rakhshandehroo, M. Salari, and M. R. Nikoo, "Optimization of degradation of ciprofloxacin antibiotic and assessment of degradation products using full factorial experimental design by Fenton Homogenous process," Global nest Journal, vol. 20, no. 2, pp. 324-332, 2018.

[22] M. Salari, G. R. Rakhshandehroo, and M. R. Nikoo, "Multiobjective optimization of ciprofloxacin antibiotic removal from an aqueous phase with Grey Taguchi method," Journal of Water and Health, vol. 16, no. 4, pp. 530-541, 2018.

[23] M. Salari, G. R. Rakhshandehroo, and M. R. Nikoo, "Degradation of ciprofloxacin antibiotic by Homogeneous Fenton oxidation: hybrid AHP-PROMETHEE method, optimization, biodegradability improvement and identification of oxidized by-products," Chemosphere, vol. 206, pp. 157-167, 2018.

[24] M. Salari, G. R. Rakhshandehroo, and M. R. Nikoo, "Developing multi-criteria decision analysis and taguchi method to optimize ciprofloxacin removal from aqueous phase," Environmental Engineering and Management Journal, vol. 18, no. 7, pp. 1543-1552, 2018, http://www.eemj.icpm.tuiasi.ro/; http://www.eemj.eu.

[25] M. Shorangiz, M. Nikoo, G. Rakhshandehroo, and M. Salari, "Optimized electro-Fenton process with sacrificial stainless steel anode for degradation/mineralization of ciprofloxacin," Process Safety and Environmental Protection, vol. 132, pp. 340-350, 2019.

[26] M. Salari, G. R. Rakhshandehroo, M. R. Nikoo, M. M. Zerafat, and M. G. Mooselu, "Optimal degradation of Ciprofloxacin in a heterogeneous Fenton-like process using $(\delta$-FeOOH $) /$ MWCNTs nanocomposite," Environmental Technology \& Innovation, vol. 23, no. 2021, Article ID 101625, 2021 b.

[27] M. Mahmoudpour, S. Gholami, M. Ehteshami, and M. Salari, "Evaluation of phytoremediation potential of vetiver grass (chrysopogon zizanioides (L.) roberty) for wastewater treatment," Advances in Materials Science and Engineering, vol. 2021, Article ID 3059983, 12 pages, 2021.

[28] S. Sohn and D. Kim, "Modification of Langmuir isotherm in solution systems-definition and utilization of concentration dependent factor," Chemosphere, vol. 58, no. 1, pp. 115-123, 2005.

[29] D. A.O, A. P. Olalekan, A. M. Olatunya, and O. J. Dada, "Langmuir, Freundlich, temkin and dubinin-radushkevich isotherms studies of equilibrium sorption of $\mathrm{Zn} \mathrm{2+}$ unto phosphoric acid modified rice husk," IOSR Journal of Applied Chemistry, vol. 3, no. 1, pp. 38-45, 2012.

[30] M. Gavrilescu, "Removal of heavy metals from the environment by biosorption," Engineering in Life Science, vol. 4, no. 3, pp. 219-232, 2004.

[31] Y. S. Ho and G. McKay, "Pseudo-second order model for sorption processes," Process Biochemistry, vol. 34, no. 5, pp. 451-465, 1999.

[32] H. Yuh-Shan, "Citation review of Lagergren kinetic rate equation on adsorption reactions," Scientometrics, vol. 59, no. 1, pp. 171-177, 2004.

[33] M. A. Hashem, "Adsorption of lead ions from aqueous solution by okra wastes," International Journal of the Physical Sciences, vol. 2, no. 7, pp. 178-184, 2007. 
[34] A. Nimibofa, N. E. Augustus, and W. Donbebe, "Modelling and interpretation of adsorption isotherms," Journal of Chemistry, vol. 2017, Article ID 3039817, 11 pages, 2017.

[35] Z. Zhu and W. Li, "Efficient adsorption and desorption of $\mathrm{Pb} 2+$ from aqueous solution," Journal of Environmental Chemical Engineering, vol. 1, no. 4, pp. 838-843, 2013.

[36] J. S. Piccin, G. L. Dotto, and A. A. Pinto, "Adsoption isotherms and therms and thermochemical Data of fd\& cred N40 binding by chitosan," Brazilian Journal of Chemical Engineering, vol. 28, no. 2, pp. 295-304, 2011.

[37] R. Wahab, F. Khan, N. K. Kaushik, J. Musarrat, and A. A. AlKhedhairy, "Photocatalytic TMO-NMs adsorbent: temperature-Time dependent Safranine degradation, sorption study validated under optimized effective equilibrium models parameter with standardized statistical analysis," Scientific Reports, vol. 7, no. 1, 2017.

[38] B. M. W. P. K. Amarasinghe and R. A. Williams, "Tea waste as a low cost adsorbent for the removal of $\mathrm{Cu}$ and $\mathrm{Pb}$ from wastewater," Chemical Engineering Journal, vol. 132, no. 1-3, pp. 299-309, 2007.

[39] T. S. Wu, L. S. Shi, and S. C. Kuo, "Alkaloids and other constituents from Tribulus terrestris," Phytochemistry, vol. 50, no. 8, pp. 1411-1415, 1999.

[40] K. Todorova, Z. Velkova, M. Stoytcheva, G. Kirova, S. Kostadinova, and V. Gochev, "Novel composite biosorbent from Bacillus cereus for heavy metals removal from aqueous solutions," Biotechnology and biotechnological equipment Journal, vol. 33, no. 1, pp. 730-738, 2019.

[41] S. Ramola, T. Belwal, C. J. Li et al., "Improved lead removal from aqueous solution using novel porous bentonite and calcite-biochar composite," The Science of the Total Environment, vol. 709, pp. 136-171, 2019.

[42] N. A. Zubir, C. Yacou, J. Motuzas, X. Zhang, X. S. Zhao, and J. C. D. C. Diniz, "The sacrificial role of graphene oxide in stabilising a Fenton-like catalyst GO-Fe3O4," Chemical Communications, vol. 51, no. 45, pp. 9291-9293, 2015.

[43] American Public Health Association (Apha), Standard Methods for the Examination of Water and Wastewater, American Water Works Association, Washington, DC, USA, twenty-first edition, 2005.

[44] A. R. Khataee, M. Safarpour, M. Zarei, and S. Aber, "Combined heterogeneous and homogeneous photodegradation of a dye using immobilized $\mathrm{TiO} 2$ nanophotocatalyst and modified graphite electrode with carbon nanotubes," Journal of Molecular Catalysis A: Chemical, vol. 363-364, pp. 58-68, 2012. 